\title{
Are There Disparities in Surgical Treatment for Breast Cancer Patients with Prior Physical Disability? A Path Analysis
}

\author{
Lena Ansmann ${ }^{a, b} \quad$ Alfred Schabmann ${ }^{c}$ Sophie Elisabeth Gross ${ }^{b, d}$ \\ Anke Gross-Kunkel ${ }^{c}$ Ute-Susann Albert ${ }^{\mathrm{e}}$ Igor Osipov ${ }^{c, f}$ \\ ${ }^{a}$ Department of Health Services Research, Faculty of Medicine and Health Sciences, Carl von Ossietzky University \\ Oldenburg, Oldenburg, Germany; ${ }^{\mathrm{b}}$ Institute for Medical Sociology, Health Services Research and Rehabilitation \\ Science (IMVR), Faculty of Human Sciences and Faculty of Medicine, University of Cologne, Cologne, Germany; \\ 'Department of Special Education and Rehabilitation, Faculty of Human Sciences, University of Cologne, Cologne,

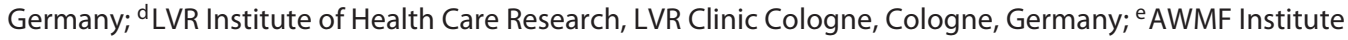

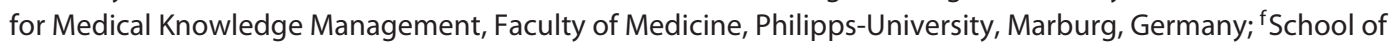 \\ Education, University of Wuppertal, Wuppertal, Germany
}

\section{Keywords}

Disability · Breast cancer · Disparities · Surgical treatment ·

Latent class analysis

\begin{abstract}
Introduction: Cancer care for patients with prior physical disability has hardly been researched in clinical research, health services research, or special education. This article aims to compare the severity of disease and the surgical treatment of diagnosed breast cancer patients with and without prior physical disability. Methods: A total of 4,194 patients with primary breast cancer who underwent surgery in a breast cancer center in North Rhine-Westphalia, Germany, participated in an annual postoperative postal survey, which was complemented by clinical data. Latent class analysis and logit path models were applied to study (1) differences in terms of UICC staging and local cancer treatment between patients with and without prior physical disability and (2) respective differences by disability severity. Results: Patients with physical disability $(n=780 ; 18.7 \%)$ had a higher chance of receiving mastectomy compared to breast-conserving therapy, even after controlling for socioeconomic
\end{abstract}

karger@karger.com

www.karger.com/brc

Karger ${ }^{\prime \prime}=$
(C) 2019 The Author(s)

Published by S. Karger AG, Basel

Karger
Open access

This article is licensed under the Creative Commons AttributionNonCommercial-NoDerivatives 4.0 International License (CC BYNC-ND) (http://www.karger.com/Services/OpenAccessLicense). Usage and distribution for commercial purposes as well as any ditribution of modified material requires written permission. status and UICC staging. Disability severity is directly and indirectly associated with receiving a mastectomy. Conclusion: In light of the research gap on disability and cancer, this work indicates disparities in care for breast cancer patients with prior physical disability. Inequalities might be attributable to (1) unequal access to care, (2) individual preferences and difficulties, or (3) medical difficulties.

๑) 2019 The Author(s)
Published by S. Karger AG, Basel

\section{Introduction}

Since persons with disabilities now live longer due to medical advances and simultaneously, the prevalence of disability rises with age, the population of people living with disability is growing [1]. According to the WHO, $15.3 \%$ of the world population live with a disability [2]. With prolonged life expectancies, their cancer risk is increasing too.

The care situation of persons with disability who develop cancer has hardly been researched, neither in oncology nor in special education. However, cancer patients with prior disability need to be studied as an independent 
group because therapeutic options must be designed to address their specific health needs, which oftentimes result from severe comorbidities, transportation and mobility problems, financial burden, stress and mental health issues, as well as prior negative experiences in healthcare [3]. While the rehabilitation of cancer survivors and resulting disabilities are increasingly studied [4], the situation of cancer patients with prior disability has seldom been the focus of research. Existing studies focus mostly on access to and utilization of cancer screening services rather than on inpatient care and treatment. Also, many of these studies investigate cancer patients with intellectual disabilities, but research on cancer care of patients with physical disability is mostly lacking. The existing studies on barriers for screening in patients with physical disability imply that the physical limitations of women with physical disability can interfere with proper screening, e.g., mammography machines are not built for women with limb deformities [5-9]. In consequence, carcinoma may be diagnosed in a later stage in women with disabilities, but findings are inconsistent $[10,11]$. Findings on disparities in mortality of breast cancer patients with disabilities are also inconsistent $[12,13]$.

Related to the treatment of breast cancer patients with prior disability, previous studies indicate that women with disabilities are less likely to undergo breast-conserving surgery (BCS) and are less likely to receive neoadjuvant chemotherapy and radiotherapy $[14,15]$. As a plausible explanation for less frequent BCS, the inability to lie flat or adequately abduct the arm, conditions that are common in women with certain disabilities, may make it difficult or impossible to deliver radiation [14]. Women who cannot undergo radiation therapy are not appropriate candidates for BCS.

Concerning the surgical treatment of breast cancer patients, clinical guidelines clearly recommend BCS over mastectomy for patients with a low risk of recurrence in order to avoid radical surgery [16]. It has been evident for many years now that BCS and mastectomy have equal survival rates $[17,18]$. However, some women decide for mastectomy despite the lack of medical indication because of the fear of recurrence or the fear of radiation therapy following BCS [19]. Moreover, for patients with mastectomy, guidelines recommend direct reconstruction (DR) of the breast if there are no oncological reasons against it and if it is the patient's preference [16, 20]. Preliminary study results point to positive emotional effects of DR for the patient [21-23]. A qualitative study identified, among others, concerns regarding body image and the reduced burden of only a single operation as the reasons expressed by patients for favoring DR. Nevertheless, many women do not undergo DR after mastectomy for various reasons, including not having been offered or informed about DR [24]. Thus, the decisions for or against
BCS and DR are preference-sensitive decisions for breast cancer patients, who should be able to make informed decisions together with their doctor by weighing the advantages and disadvantages of treatment options [25]. However, research on the needs and preferences of breast cancer patients with physical disability regarding treatment options and decision-making is still sparse.

This article examines potential disparities in severity of disease and surgical treatment in inpatient care for diagnosed primary breast cancer patients with prior physical disability. Therefore, we compared the somatic care (BCS vs. mastectomy, DR yes vs. no) of diagnosed breast cancer patients with and without prior physical disability.

\section{Materials and Methods}

\section{Study Design and Sample}

Data were collected from a postal survey of a consecutive sample of patients from 83 breast cancer center hospitals in North Rhine-Westphalia. The survey data were supplemented with clinical data provided by the hospital staff. Patients were included if they (1) had undergone inpatient surgery between February 1 and July 31,2014 , for newly diagnosed breast cancer, (2) had at least one malignancy, and (3) had at least one postoperative histological evaluation. The survey was approved by the Ethics Committee of the Medical Faculty of the University of Cologne. Further details on the survey have been reported elsewhere [26, 27].

\section{Instruments}

Patients were surveyed with the Cologne Patient Questionnaire for Breast Cancer (CPQ-BC 2.0) [26], which assesses patients' perceptions of several aspects of hospital care as well as sociodemographic and disease-related patient characteristics. Patients were asked "Did you have an officially recognized disability prior to the breast cancer diagnosis?" with the response options being "Yes" and "No." Patients answering "Yes" were additionally asked "What is your degree of disability?" (response in \%) and "What type of disability do you have?" with the categories "physical," "intellectual," and/or "psychological." In the German health and social care system, disability is classified into degrees of disability between 20 and 100 based on the degree of functional impairment assessed in medical reports. The degree of disability is also disclosed in ID cards for persons with severe disability $(\geq 50)$. Patients provided sociodemographic information, and clinical data were collected on cancer stage (using the International Union against Cancer [UICC] staging system based on tumor size, metastases, and lymph node involvement) and type of surgery (BCS vs. mastectomy with DR vs. mastectomy without DR) (see Table 1 for details).

\section{Analysis}

The analysis excludes patients with psychological and intellectual disabilities due to the high heterogeneity between the three forms of disability assessed in the survey and the low number of surveyed patients with a psychological and intellectual disability. Data analysis consisted of the two following procedures. In a first step, we employed a person-oriented approach and clustered the patients according to their socioeconomic status (SES) and age using latent class analysis (LCA). LCA is a model-based statistical procedure which is used for clustering individuals into homoge- 
Table 1. Descriptive results with respect to clinical and socioeconomic background data of patients with and without physical disability

\begin{tabular}{|c|c|c|c|c|}
\hline Variable & Response & $\begin{array}{l}\text { No disability, } \\
n(\%)\end{array}$ & $\begin{array}{l}\text { With physical } \\
\text { disability, } n(\%)\end{array}$ & $\begin{array}{l}\chi^{2}(\mathrm{df}) \\
p \text { value }\end{array}$ \\
\hline UICC stage & $\begin{array}{l}\text { Stage } 0 \\
\text { Stage I } \\
\text { Stage II } \\
\text { Stage III } \\
\text { Stage IV } \\
\text { Missing }\end{array}$ & $\begin{aligned} & 348(11.1) \\
& 1,146(36.5) \\
& 971(30.9) \\
& 287(9.1) \\
& 73(2.3) \\
& 317(10.1)\end{aligned}$ & $\begin{aligned} 73 & (9.4) \\
312 & (40.0) \\
220 & (28.2) \\
66 & (8.5) \\
31 & (4.0) \\
78 & (10.0)\end{aligned}$ & $\begin{array}{l}12.04(4) \\
<0.05\end{array}$ \\
\hline Type of surgery & $\begin{array}{l}\text { Mastectomy without direct reconstruction } \\
\text { Mastectomy with direct reconstruction } \\
\text { Breast-conserving surgery } \\
\text { Missing }\end{array}$ & $\begin{aligned} 542 & (17.3) \\
233 & (7.4) \\
2,268 & (72.2) \\
99 & (3.2)\end{aligned}$ & $\begin{aligned} 184 & (23.6) \\
37 & (4.7) \\
531 & (68.1) \\
28 & (3.6)\end{aligned}$ & $\begin{array}{l}21.57(2) \\
<0.001\end{array}$ \\
\hline $\begin{array}{l}\text { Health insurance } \\
\text { status }\end{array}$ & $\begin{array}{l}\text { Statutory } \\
\text { Statutory with additional private } \\
\text { Private } \\
\text { Missing }\end{array}$ & $\begin{array}{r}2,194(69.8) \\
541(17.2) \\
374(11.9) \\
33(1.1)\end{array}$ & $\begin{array}{c}508(74.4) \\
119(15.3) \\
74(9.5) \\
7(0.9)\end{array}$ & $\begin{array}{l}6.43(2) \\
<0.05\end{array}$ \\
\hline Age & $\begin{array}{l}18-39 \\
40-49 \\
50-59 \\
60-69 \\
70-79 \\
\geq 80 \\
\text { Missing }\end{array}$ & $\begin{array}{l}116(3.7) \\
551(17.5) \\
937(29.8) \\
773(24.6) \\
597(19.0) \\
151(4.8) \\
17(0.5)\end{array}$ & $\begin{array}{c}7(0.9) \\
42(5.4) \\
177(22.7) \\
280(35.9) \\
198(25.4) \\
72(9.2) \\
4(0.5)\end{array}$ & $\begin{array}{l}151.52(5), \\
<0.001\end{array}$ \\
\hline $\begin{array}{l}\text { Highest secondary } \\
\text { school qualification }\end{array}$ & $\begin{array}{l}\text { No lower secondary school education } \\
\text { Lower secondary school education } \\
\text { Intermediate secondary school education } \\
\text { Higher secondary school education* } \\
\text { Missing }\end{array}$ & $\begin{aligned} 43 & (1.4) \\
1,254 & (39.9) \\
872 & (27.8) \\
912 & (29.0) \\
61 & (1.9)\end{aligned}$ & $\begin{array}{c}16(2.1) \\
415(53.2) \\
198(25.4) \\
136(17.4) \\
15(1.9)\end{array}$ & $\begin{array}{l}60.58(3) \\
<0.001\end{array}$ \\
\hline Employment status & $\begin{array}{l}\text { Full-time employment } \\
\text { Part-time employment } \\
\text { Homemaker } \\
\text { Unemployed } \\
\text { Retiree } \\
\text { Missing }\end{array}$ & $\begin{array}{c}741(23.6) \\
706(22.4) \\
448(14.3) \\
147(4.7) \\
1,028(32.7) \\
71(2.3)\end{array}$ & $\begin{aligned} 11 & (14.2) \\
80 & (10.2) \\
69 & (8.8) \\
40 & (5.1) \\
459 & (58.8) \\
21 & (2.7)\end{aligned}$ & $\begin{array}{l}198.99(4), \\
<0.001\end{array}$ \\
\hline
\end{tabular}

* University or university of applied sciences entrance certificate.

neous groups (latent classes) with respect to an array of observed categorical variables $[28,29]$. A series of latent class models with one through five latent classes based on secondary school education (low/intermediate/high secondary school degree), current employment status (full or part-time employed/unemployed/ homemaker/retiree), health insurance profile (statutory/private health insurance/statutory health insurance with additional private insurance), and age (as a covariate) were estimated in order to identify underlying subgroups in the population of patients with regard to socioeconomic background. Selection from the set of models with different numbers of latent classes was accomplished based on information criteria (AIC and BIC) and the adjusted LoMendell-Rubin likelihood ratio test together with bootstrap likelihood ratio test. Additional criteria in terms of model selection were also considerations regarding the interpretability of a particular solution, or in other words, identification of distinct logical patterns of latent subgroups. Individuals, then, were assigned to the class for which they have the highest posterior probability of membership [30, 31].
In a second step, two logit path models were estimated to predict the type of surgical treatment, taking into account the UICC staging and controlling for LCA class membership as an indicator for SES and age. The main advantage of path analysis is the estimation of complex models where relationships between dependent and independent variables as well as between dependent variables are modelled simultaneously. Finally, the relationships between variables in estimated logit path models are presented in odds ratios.

The first logit path model included patients with and without physical disability in order to compare the two groups with regard to surgical treatment. In the second model, only patients with physical disabilities were included in order to compare the surgical treatment by severity of disability. All models were estimated with Mplus 7.2 using full-information maximum likelihood estimation, which allowed for handling missing data within the models without imputation. In the path analysis, the disability indicator variable and UICC staging were reverse coded for purposes of better interpretability of results. 


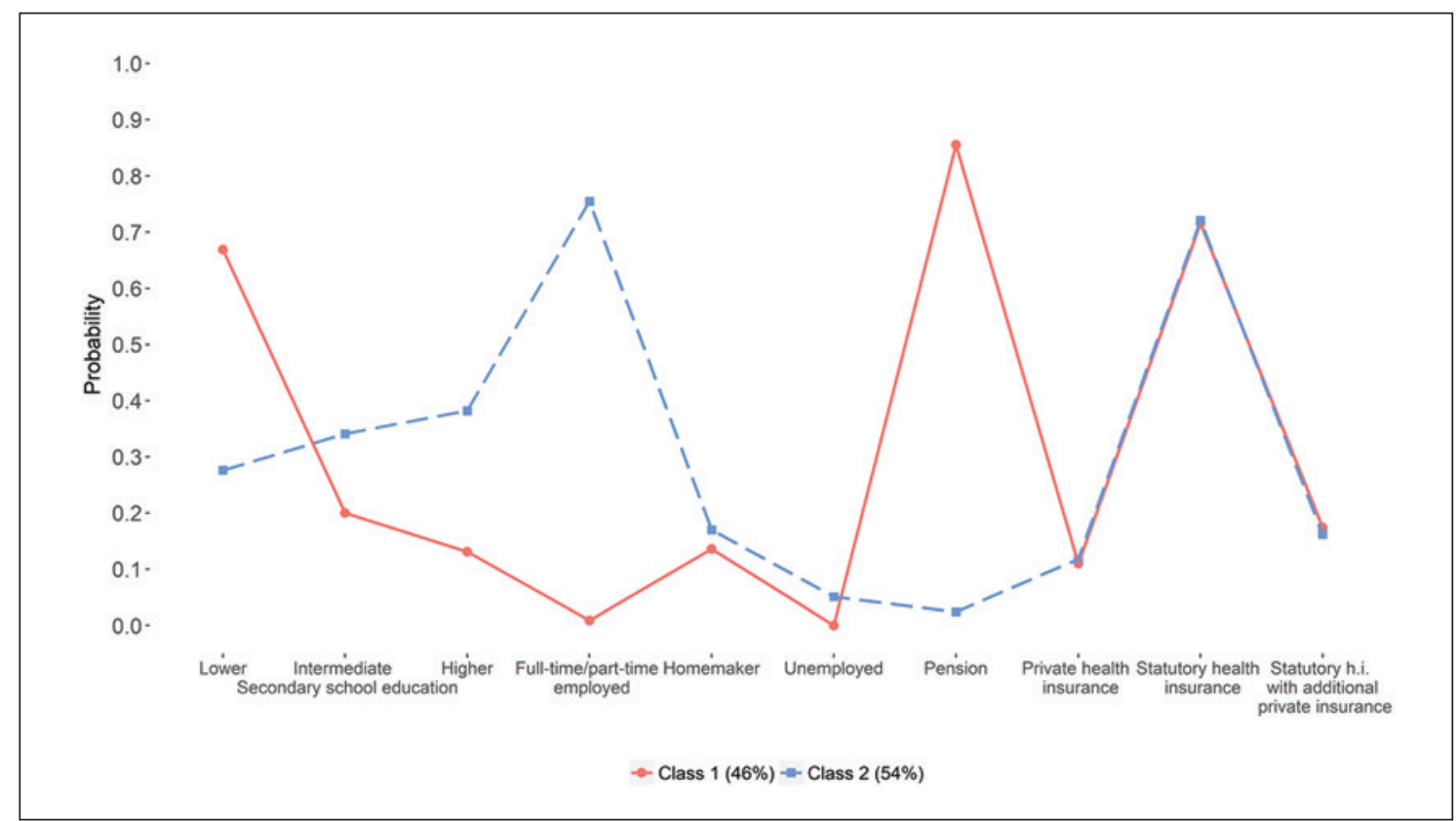

Fig. 1. Model-estimated, class-specific response probability profile plot for the two-class LCA.

\section{Results}

\section{Descriptive Results}

Of the total of 5,653 primary breast cancer patients who underwent surgery in one of the breast cancer center hospitals in North Rhine-Westphalia between February and July 2014, 4,808 agreed to participate in the survey and formed the sample of potential respondents. Of these, 4,194 returned completed questionnaires (response rate of consenting patients: $87.2 \%$ ). The sample consisted of 780 patients $(18.7 \%)$ with a physical disability and 3,142 patients without any disability. The clinical and socioeconomic characteristics of patients with a physical disability and patients without any disability are shown in Table 1 (see online suppl. Fig 1 for the distribution of the degrees of disability; for all online suppl. material, see www. karger.com/doi/10.1159/000503777). Regarding clinical data, the descriptive results reveal inequalities in the distribution of UICC stages and the type of received surgical treatment among patients with physical disability and those without any disability.

\section{Results of LCA of SES and Age}

Absolute and relative model fit statistics were used as criteria in the model selection process (see online suppl. Table 1). The two-class model was selected because of easy identification, greater parsimony, and more substantive interpretation of latent subgroups patterns derived from estimated conditional response probabilities (see Fig. 1). The first latent class in our sample of patients with and without physical disability is comprised of older pa- tients with an average age of 72 years $(\mathrm{SD}=6.72)$, who were very likely to report a lower level of school education $(p=0.67)$ and being currently retired $(p=0.86)$. The second latent class is characterized by quite similar probabilities of the three levels of school education, with the higher level being most probable $(p=0.38)$. Patients in this class were substantially younger than those in class one, on average 52 years old ( $\mathrm{SD}=7.17)$, and very likely to report full- or part-time employment $(p=0.76)$ as their current status as well as having statutory health insurance $(p=0.72)$. Individuals in the second class did not differ from patients in the first class in terms of health insurance and being unemployed or housewives. Overall, the first subgroup comprises older, less educated patients in retirement, and makes up $46 \%$ of the sample. The second subgroup encompasses middle-aged employed and better educated patients, making up $54 \%$ of the sample.

\section{Results of Logit Path Analysis}

Comparing patients with and without physical disabilities, the first path model showed that the latter were at 2.57 times greater odds of being in the second latent class comprising middle-aged employed and better educated patients (see Fig. 2 and online suppl. Table 2). Controlled for latent class membership (based on SES and age) and UICC staging, furthermore, having no physical disability increased the odds of receiving BCS by 1.27 , but not of undergoing mastectomy with DR, both compared to mastectomy without DR. Regarding UICC staging as an indicator of severity of disease, there were no differences between patients with and without physical disability when 
Fig. 2. Logit path model 1 (odds ratios). $N=3,922 .^{*} p<0.05,{ }^{* * *} p<0.001$; n.s., not significant $(p>0.05)$. BCS, breast-conserving surgery; MDR, mastectomy with direct reconstruction; MWDR, mastectomy without direct reconstruction; SES, socioeconomic status.
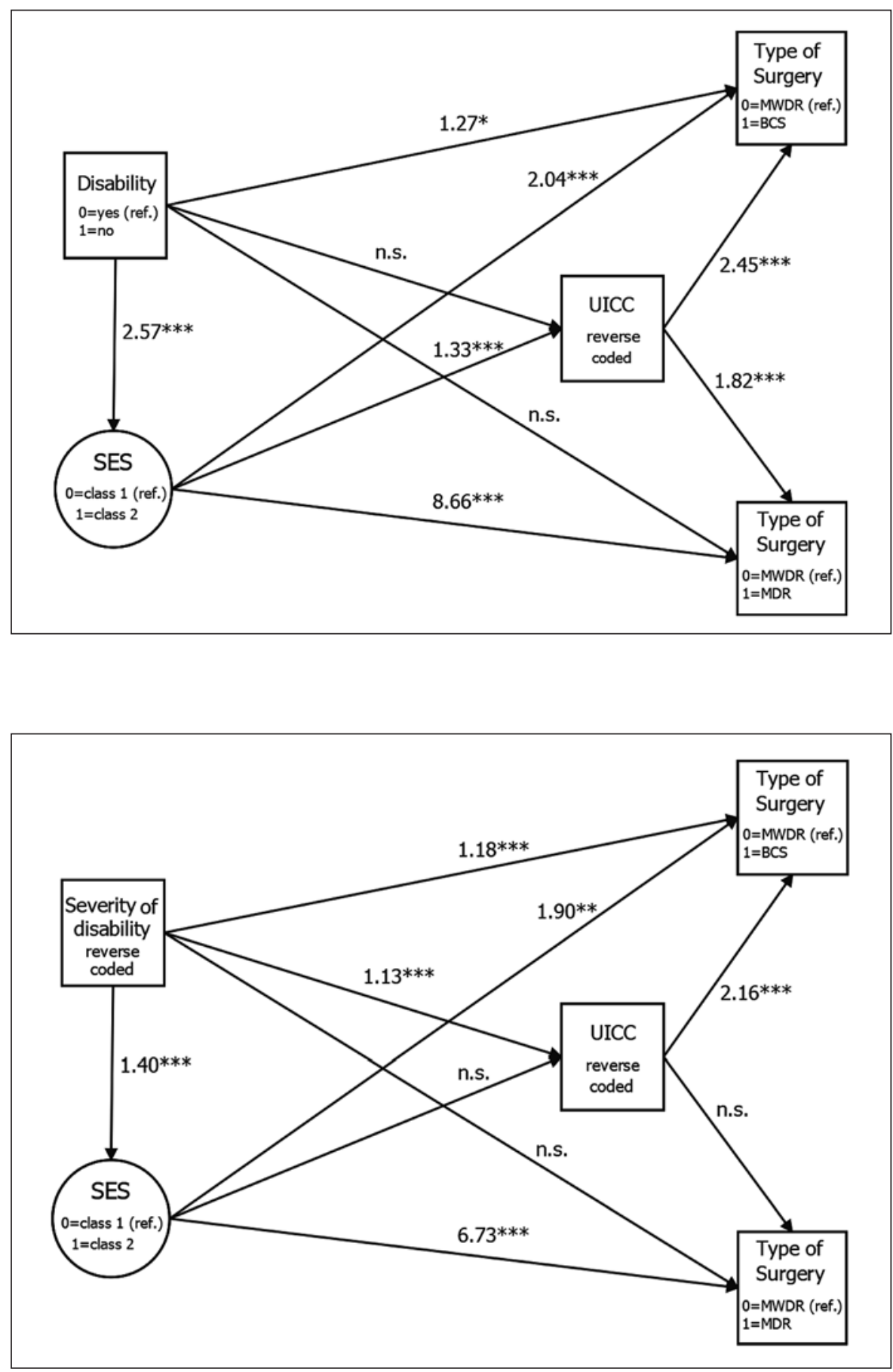

Fig. 3. Logit path model 2 (odds ratios). $N=780 .{ }^{* *} p<0.01,{ }^{* * *} p<0.001$; n.s., not significant $(p>0.05)$. BCS, breast-conserving surgery; MDR, mastectomy with direct reconstruction; MWDR, mastectomy without direct reconstruction; SES, socioeconomic status.

lower UICC stages (odds ratio $=1.13$ ). Moreover, patients with lower levels of disability were 1.4 times more likely to be in latent class two, among middle-aged, better educated patients.

\section{Discussion}

This study aimed to examine potential disparities in disease severity and surgical treatment between inpatient breast cancer patients with prior physical disability and 
patients without prior disability. The data showed that breast cancer patients with prior physical disability have significantly higher chances of receiving mastectomy rather than BCS, although transformed into Cohen's measure of effect size, it yields a rather small effect of $d=$ 0.13 . This even holds true when age-related and socioeconomic differences between patients with or without disability were accounted for. This result is in line with Caban et al. [14] and McCarthy et al. [15], who found similar results in breast cancer patients in the US. Since our data showed no significant association between physical disability and UICC staging when controlling for socioeconomic background and age, we cannot confirm that breast cancer patients with disability are being diagnosed in a later and more severe stage. Prior studies investigating a potentially delayed diagnosis have shown an inconsistent picture $[10,14]$. Since there are no differences in UICC staging between patients with or without a physical disability, staging and age cannot explain the higher rate of mastectomy in patients with physical disability. Nevertheless, independent of disability status, UICC staging is strongly associated with the type of surgery, as was to be expected due to recommendations in clinical guidelines [16]. Moreover, whereas the receipt of BCS is dependent on disability status, the decision of patients with mastectomy for or against DR is independent of physical disability. The study also revealed that the severity of disability plays an important role in explaining differences in surgical treatment between patients with and without physical disability. A low severity of physical disability was associated with a higher chance of receiving BCS but was not associated with receiving DR after mastectomy. Thus, whereas the decision for BCS is dependent on the severity of disability, the decision of patients with mastectomy for or against DR is again independent from disability severity. This also highlights the fact that physical disabilities are very heterogeneous and thus the severity of disability does play a role in determining treatment decisions.

The disparities found raise questions about the quality of breast cancer care for the population of women with physical disabilities. The disparities found are poorly understood and might be attributable to different aspects, which deserve further research. Firstly, the disparities might reflect inequalities in access to treatment options due to the treating doctors providing selective information on those options. In addition, disability can complicate the patient-doctor communication [32-34], leading to unopen or uninformed decision-making talks, where the weighing of advantages and disadvantages of BCS versus mastectomy is insufficiently addressed. Secondly, the disparities in type of surgery can be attributed to patients' preferences and individual difficulties. Some patients with physical disability might decide against BCS out of a wish for shortened treatment duration without radiation therapy due to their previous frequent experiences with medical care. In addition, individual difficulties such as transportation problems to the clinic for radiation therapy might play a substantial role for patients with limited mobility (e.g., use of wheelchair). Furthermore, studies have shown that physical limitations prevent women from receiving mammography since the $\mathrm{X}$-ray machines are not built for patients with physical limitations [5-9, 35]. Thirdly, medical difficulties associated with or additional to physical disability may speak against certain treatment options. A high tumor grade, inflammatory cancer, complex comorbidities, and the type of disability, such as spinal cord injury, may not permit BCS with DR $[14,16]$.

In line with existing studies [36], a social gradient in the prevalence of physical disability is evident in our sample. The lower the SES, the higher the chance of having a physical disability. Furthermore, higher SES predicts lower UICC stage in our data, implying that patients with low SES either have a delayed cancer diagnosis due to decreased utilization of mammography [37] and methods of self-detection or have a higher risk of severe cancer [38]. However, when restricting the same analysis to patients with physical disability only and to disability severity, the association between SES and UICC staging vanishes, indicating that the association between status and staging is mediated by physical disability and its severity. Moreover, the analyses reveal the importance of the socioeconomic background in treatment decision-making. The chances of receiving BCS as well as the chances of receiving DR after mastectomy increase with higher SES. Yet, it is unclear whether this social gradient can be explained by lower health literacy in lower socioeconomic groups influencing treatment decision-making, the communication behavior of doctors regarding the treatment decision, which may differ by patient status, or differing patient preferences [39, 40].

\section{Strengths and Limitations}

Several limitations should be considered when interpreting the results of this study and when planning further related studies. First, the cross-sectional design of the study does not allow for causal interpretations. The collected data did encompass self-reported information on the severity of disability but not on types and duration of physical disability (e.g., mobility impairment, congenital or acquired disability), which may substantially influence treatment decisions. The self-reports of type of disability and disability severity are of potentially limited validity since it is unclear how patients derive their degree of severity (e.g., from a severe disability pass). The generalizability of the results is restricted to a well-defined local sample of patients treated in breast cancer centers in 
North Rhine-Westphalia, the most populous German state. However, the large sample of more than 4,000 patients, the high response rate, the additional clinical data, and the comparability with national data on breast cancer patients highlight the good quality of the data, especially in this understudied field.

\section{Conclusion}

In light of the research gap on disability and cancer, this work indicates disparities in care for breast cancer patients with prior physical disability, which need to be explored in depth in further studies. Among others, the following are relevant questions to be answered in subsequent studies: (1) which determinants on the patient, provider and societal level account for the found disparities, (2) can disparities be observed for intellectual and psychological disabilities as well, and (3) how can providers and health care organizations improve the care of patients with prior disability?

\section{Acknowledgement}

The authors thank all hospitals and patients who took part in the surveys. We would also like to thank Markus Alich and his team for technical support.

\section{Statement of Ethics}

The survey was approved by the Ethics Committee of the Medical Faculty of the University of Cologne. All patients gave their written informed consent.

\section{Disclosure Statement}

The authors have no conflicts of interest to declare.

\section{Funding Sources}

This research did not receive any specific grant from funding agencies in the public, commercial, or not-for-profit sectors. The patient survey in the presented study was financed by the participating breast cancer centers themselves as part of the accreditation from the Physician Chamber Westphalia-Lippe. The breast cancer centers themselves were not involved in the preparation of data or the manuscript.

\section{Author Contributions}

L.A. and S.E.G. conducted the data acquisition. L.A., I.O., and A.S. contributed to data analysis. I.O. and L.A. drafted the work. All authors substantially contributed to the interpretation of data and to the revision of the draft. All authors finally approved the version and are accountable for the work.

\section{References}

1 Guzman-Castillo M, Ahmadi-Abhari S, Bandosz P, Capewell S, Steptoe A, Singh-Manoux A, et al. Forecasted trends in disability and life expectancy in England and Wales up to 2025: a modelling study. Lancet Public Health. 2017 May;2(7):e307-13.

2 World Health Organization. World Bank: World report on disability, World Health Organization, World Bank, 2011. http://www. who.int/iris/handle/10665/44575 (accessed November 21, 2017).

3 Nosek MA. The John Stanley Coulter lecture. Overcoming the odds: the health of women with physical disabilities in the United States. Arch Phys Med Rehabil. 2000 Feb;81(2):135-8.

4 Silver JK, Baima J, Mayer RS. Impairmentdriven cancer rehabilitation: an essential component of quality care and survivorship. CA Cancer J Clin. 2013 Sep;63(5):295-317.

5 Iezzoni LI, McCarthy EP, Davis RB, Siebens H. Mobility impairments and use of screening and preventive services. Am J Public Health. 2000 Jun;90(6):955-61.

6 Kirschner KL, Breslin ML, Iezzoni LI. Structural impairments that limit access to health care for patients with disabilities. JAMA. 2007 Mar;297(10):1121-5.

7 Peters K, Cotton A. Environmental, structural and process barriers in breast cancer screening for women with physical disability: A qualitative study. Radiography. 2016; 22(3):e184-9.
8 Andresen EM, Peterson-Besse JJ, Krahn GL, Walsh ES, Horner-Johnson W, Iezzoni LI. Pap, mammography, and clinical breast examination screening among women with disabilities: a systematic review. Womens Health Issues. 2013 Jul-Aug;23(4):e20514.

9 Horner-Johnson W, Dobbertin K, Iezzoni LI. Disparities in receipt of breast and cervical cancer screening for rural women age 18 to 64 with disabilities. Womens Health Issues. 2015 May-Jun;25(3):246-53.

10 Satgé D, Sauleau EA, Jacot W, Raffi F, Azéma B, Bouyat JC, et al. Age and stage at diagnosis: a hospital series of 11 women with intellectual disability and breast carcinoma. BMC Cancer. 2014 Mar;14(1):150.

11 Roetzheim RG, Chirikos TN. Breast cancer detection and outcomes in a disability beneficiary population. J Health Care Poor Underserved. 2002 Nov;13(4):461-76.

12 Strauss D, Cable W, Shavelle R. Causes of excess mortality in cerebral palsy. Dev Med Child Neurol. 1999 Sep;41(9):580-5.

13 Wisdom JP, McGee MG, Horner-Johnson W, Michael YL, Adams E, Berlin M. Health disparities between women with and without disabilities: a review of the research. Soc Work Public Health. 2010 May;25(3):36886

14 Caban ME, Nosek MA, Graves D, Esteva FJ, $\mathrm{McNeese} \mathrm{M}$. Breast carcinoma treatment re- ceived by women with disabilities compared with women without disabilities. Cancer. 2002 Mar;94(5):1391-6.

15 McCarthy EP, Ngo LH, Roetzheim RG, Chirikos TN, Li D, Drews RE, et al. Disparities in breast cancer treatment and survival for women with disabilities. Ann Intern Med. 2006 Nov; 145(9):637-45.

16 Senkus E, Kyriakides S, Penault-Llorca F, Poortmans P, Thompson A, Zackrisson S, et al.; ESMO Guidelines Working Group. Primary breast cancer: ESMO Clinical Practice Guidelines for diagnosis, treatment and follow-up. Ann Oncol. 2013 Oct;24 Suppl 6:vi723.

17 Veronesi U, Cascinelli N, Mariani L, Greco M, Saccozzi R, Luini A, et al. Twenty-year follow-up of a randomized study comparing breast-conserving surgery with radical mastectomy for early breast cancer. N Engl J Med. 2002 Oct;347(16):1227-32.

18 Early Breast Cancer Trialists' Collaborative Group. Effects of radiotherapy and surgery in early breast cancer. An overview of the randomized trials. N Engl J Med. 1995 Nov; 333(22):1444-55

$19 \mathrm{Gu}$ J, Groot G, Holtslander L, Engler-Stringer R. Understanding Women's Choice of Mastectomy Versus Breast Conserving Therapy in Early-Stage Breast Cancer. Clin Med Insights Oncol. 2017 Feb; 11: 1179554917691266. 
20 Hartrampf J, Ansmann L, Wesselmann S, Beckmann MW, Pfaff H, Kowalski C. Influence of Patient and Hospital Characteristics on the Performance of Direct Reconstruction after Mastectomy. Geburtshilfe Frauenheilkd. 2014 Dec;74(12):1128-36.

21 Fernández-Delgado J, López-Pedraza MJ, Blasco JA, Andradas-Aragones E, SánchezMéndez JI, Sordo-Miralles G, et al. Satisfaction with and psychological impact of immediate and deferred breast reconstruction. Ann Oncol. 2008 Aug;19(8):1430-4.

22 D’Souza N, Darmanin G, Fedorowicz Z. Immediate versus delayed reconstruction following surgery for breast cancer. Cochrane Database Syst Rev. 2011 Jul;(7):CD008674.

23 Eriksen C, Frisell J, Wickman M, Lidbrink E, Krawiec K, Sandelin K. Immediate reconstruction with implants in women with invasive breast cancer does not affect oncological safety in a matched cohort study. Breast Cancer Res Treat. 2011 Jun;127(2): 439-46.

24 Weenk M, Wunschel P, Heine E, Strobbe LJ. Factors influencing the decision to pursue immediate breast reconstruction after mastectomy for breast cancer. Gland Surg. 2017 Feb; 6(1):43-8.

25 Stiggelbout AM, Van der Weijden T, De Wit MP, Frosch D, Légaré F, Montori VM, et al. Shared decision making: really putting patients at the centre of healthcare. BMJ. 2012 Jan;344 jan27 1:e256.
26 Ansmann L, Kowalski C, Pfaff H. Ten Years of Patient Surveys in Accredited Breast Centers in North Rhine-Westphalia. Geburtshilfe Frauenheilkd. 2016 Jan;76(1):37-45.

27 Ansmann L, Kowalski C, Pfaff H, Wuerstlein R, Wirtz MA, Ernstmann N. Patient participation in multidisciplinary tumor conferences. Breast. 2014 Dec;23(6):865-9.

28 Collins LM, Lanza ST. Latent Class and Latent Transition Analysis. Hoboken (NJ): Wiley; 2010.

29 Wang J, Wang X. Structural equation modeling. London: Wiley; 2012. https://doi. org/10.1002/9781118356258.

30 Bray BC, Lanza ST, Tan X. An Introduction to Eliminating Bias in Classify-Analyze Approaches for Latent Class Analysis. Technical Report Series. Pennsylvania: Pennsylvania State University, College of Health and $\mathrm{Hu}$ man Development, The Methodology Center; 2012.

31 Clogg CC. Latent class models: Recent developments and prospects for the future. In: Arminger G, Clogg CC, Sobel ME, editors. Handbook of statistical modeling for the social and behavioral sciences. New York: Plenum Press; 1995. pp. 311-59.

32 Denny E. When Walking Fails: Mobility Problems of Adults with Chronic Conditions - by Iezzoni, L.I. Sociol Health Illn. 2007; 29(5):788-9.

33 Olkin R. What psychotherapists should know about disability. New York: Guilford Press; 1999.
34 Iezzoni LI, Davis RB, Soukup J, O’Day B. Quality dimensions that most concern people with physical and sensory disabilities. Arch Intern Med. 2003 Sep;163(17):2085-92.

35 Nosek MA, Howland CA. Breast and cervical cancer screening among women with physical disabilities. Arch Phys Med Rehabil. 1997 Dec;78(12 Suppl 5):S39-44.

36 Singh GK, Lin SC. Marked ethnic, nativity, and socioeconomic disparities in disability and health insurance among US children and adults: the 2008-2010 American community survey. BioMed Res Int. 2013;2013:627412.

37 Calo WA, Vernon SW, Lairson DR, Linder SH. Area-level Socioeconomic Inequalities in the Use of Mammography Screening: A Multilevel Analysis of the Health of Houston Survey. Womens Health Issues. 2016 Mar-Apr;26(2):201-7.

38 Kuznetsov L, Maier W, Hunger M, Meyer M, Mielck A. Associations between regional socioeconomic deprivation and cancer risk: analysis of population-based Cancer Registry data from Bavaria, Germany. Prev Med. 2011 Oct;53(4-5):328-30.

39 Popescu I, Schrag D, Ang A, Wong M. Racial/ Ethnic and Socioeconomic Differences in Colorectal and Breast Cancer Treatment Quality: The Role of Physician-level Variations in Care. Med Care. 2016 Aug;54(8):780-8.

40 Pollitt RA, Swetter SM, Johnson TM, Patil P, Geller AC. Examining the pathways linking lower socioeconomic status and advanced melanoma. Cancer. 2012 Aug;118(16):400413. 